dernde Mission ist als eine die Realität verändernde Aktivität, aber auch als Notwendigkeit der Selbstveränderung zu verstehen (511). Dies impliziert eine kritische Einstellung gegenüber einem als Kerygma, Koinonia, Diakonia, Martyria und Leitourgia definierten Missionsverständnis (Rütti): „We need a more radical and comprehensive hermeneutic of mission" $(399,512)$. Deren facettenreiche Realität verankert Bosch christologisch in der Inkarnation, Kreuzigung, Auferstehung und Erhöhung Jesu, sowie in Pfingsten und der Parusie. Es ist bezeichnend, $\mathrm{daß}$ gerade hier Moltmann mit seiner christologisch und pneumatologisch akzentuierten Hermeneutik der Sendung nochmals stark präsent ist. Die hermeneutische Frage nach der Mission - Ausgangspunkt unseres Überblicks - beantwortet Bosch am Schluß seines Werks mit einer Formulierung, die zugleich als eine Art Zusammenfassung und Ergebnis unseres Rundgangs gelten kann:

"Mission is not competition with other religions, not a conversion activity, not expanding the faith, not building up the kingdom of God; neither is it social, economic, or political activity. And yet, there is merit in all these projects. So, the church's concern is conversion, church growth, the reign of God, economy, society and politics - but in a different manner! The missio Dei purifies the church. It sets it under the cross - the only place where it is ever safe. The cross is the place of humiliation and judgment, but it is also the place of refreshment and new birth. As community of the cross the church then constitutes the fellowship of the kingdom, not just church members; as community of the exodus, not as a religious institution, it invites people to the feast without end" (519).

\title{
Theologie in Afrika und Asien
}

Christine Lienemann-Perrin

\section{Afrika}

Afrikanische Spiritualität und christlicher Glaube. Erfahrungen der Inkulturation, hg. von Mulago gwa Cikala Musharhamina (L'Afrique et ses formes de vie spirituelle, Kinshasa 1983; übers. von U. Faymonville. Theologie der Dritten Welt 8), 198 S. Herder Freiburg i. Br./Basel/Wien 1986. - Oskar Bimwenyi-Kweshi, Alle Dinge erzäblen von Gott. Grundlegung afrikanischer Theologie (Discours Théologique Négro-Africain. Problème des Fondements, Paris 1981; übers. von U. Faymonville, gekürzte dt. Ausgabe, bearbeitet und eingeführt von T. Kramm. Theologie der Dritten Welt 3), 180 S. Herder Freiburg i.Br./Basel/Wien 1982. 1987². - Allan A. Boesak, Gerechtigkeit erböht ein Volk. Texte aus dem Widerstand (übers. und hg. von H.-H. Nordholt), $128 \mathrm{~S}$. Neukirchener Vlg NeukirchenVluyn 1985. - Ders., Schreibe dem Engel Südafrikas. Trost und Protest in der Apokalypse des Johannes (Troost en Protest. Reflecties op de Openbaring van Johannes, Baarn 1987; englisch: Comfort and Protest. The Apocalypse from a South African Perspective; aus dem Englischen übers. von S. Hinz-Wegener und R. Hinz), $158 \mathrm{~S}$. Kreuz Stuttgart 1988. $-F$. Eboussi Boulaga, Christianity without Fetishes. An African Critique and Recapture of Christianity (Christianisme sans fétiche, Paris 1981, übers. von R. R. Barr), 238 S. Orbis Books Maryknoll, N. Y. 1984. - Bénézet Bujo, African Christian Morality at the Age of In- 
culturation, 137 S. St. Paul Publications Africa Nairobi 1990. - Ders., Afrikanische Theologie in ihrem gesellschaftlichen Kontext (Theologie interkulturell 1), 151 S. Patmos Düsseldorf 1986. - Der schwarze Christus. Wege afrikanischer Christologie, mit Beiträgen von Yvette Akle u. a. (Chemins de la Christologie africaine, Paris 1986; übers. von U. Faymonville. Theologie der Dritten Welt 12), 206 S. Herder Freiburg i.Br./Basel/Wien 1989, darin: Cécé Kolié, Jesus - Heiler, 108-137. - Jean-Marc Ela, Mein Glaube als Afrikaner. Das Evangelium in schwarzafrikanischer Lebenswirklichkeit (Ma foi d'Africain, Paris 1985; übers. von U. Faymonville. Theologie der Dritten Welt 10), $198 \mathrm{~S}$. Herder Freiburg i. Br./Basel/Wien 1987. - Rudolf Hinz/Frank Kürschner-Pelkmann (Hg.) Christen im Widerstand. Die Diskussion um das südafrikanische KAIROS Dokument (Texte 40), 267 S. Vlg Dienste in Übersee Stuttgart 1987. - John S. Mbiti, Bibel und Theologie im afrikanischen Christentum, hg. von Gudrun Löwner (Bible and Theology in African Christianity, Nairobi 1986; übers. von B. Ferrazzini. ThÖ 22), 212 S. Vandenhoeck \& Ruprecht Göttingen 1987. - Alben Nolan, Gott in Südafrika. Die Herausforderung des Evangeliums (God in South Africa: The Challenge of the Gospel, Claremont/Südafrika 1988; übers. von E. Arens), 270 S. Edition Exodus Fribourg/Brig 1989. - Mercy Amba Oduyoye, Wir selber haben ihn gebört. Theologische Reflexionen zum Christentum in Afrika (Hearing and Knowing. Theological Reflections on Christianity in Africa, Orbis Books Maryknoll, N. Y. 1986; übers. von K. Hermans), 228 S. Edition Exodus, Fribourg/Brig 1988. - Anselme Titianma Sanon, Das Evangelium verwurzeln. Glaubenserschließung im Raum afrikanischer Stammesinitiationen (Enraciner l'Evangile. Initiations africaines et pédagogie de la Foi, Paris 1982; übers. von U. Faymonville. Theologie der Dritten Welt 7), $156 \mathrm{~S}$. Herder Freiburg i.Br./Basel/Wien 1985. - Gabriel M. Setiloane, Der Gott meiner Väter und mein Gott. Afrikanische Theologie im Kontext der Apartheid (aus dem Englischen übers. und hg. von I. Peters), 122 S. Hammer Wuppertal 1988.

\section{Asien}

Byung-Mu Abn, Draußen vor dem Tor. Kirche und Minjung in Korea. Theologische Beiträge und Reflexionen, hg. von Winfried Glüer (ThÖ 20), 156 S. Vandenhoeck \& Ruprecht Göttingen 1986. - Mary Rosario Battung u. a. (Hg.), Theologie des Kampfes. Christliche Nachfolgepraxis in den Philippinen (Religion and Society: Towards a Theology of Struggle. Book 1, Manila 1988; übers. von E. Arens u. 2., Theologie und Kirche im Prozeß der Befreiung 8), 240 S. edition liberación Münster 1989. - Benigno P. Beltran, Philippinische Theologie in ibrem kulturellen und gesellschaftlichen Kontext (Theologie interkulturell 3), 172 S. Patmos Düsseldorf 1988. - Feliciano V. Cariño (Hg.), Gleich einem Senfkom. Kommentare zum Glaubensbekenntnis der Vereinigten Kirche Christi auf den Philippinen (UCCP) (Like a Mustard Seed. Commentaries on the Statement of Faith of the United Church of Christ in the Philippines, 1987; Übers. und Redaktion von P. Heinsius), 83 S. $\mathrm{Vlg}$ der Vereinigten Evangelischen Mission Wuppertal, 2. verbesserte Aufl. 1989. - Soo-II Chai, Die messianische Hoffnung im Kontext Koreas (Perspektiven der Weltmission. Wissenschaftliche Beiträge 10), $185 \mathrm{~S}$. Vlg an der Lottbek Hamburg 1990. - Chinesischer Christenrat, Die christliche Lebre, erklärt für alle Anfänger im Glauben (Hg. der deutschen Ausgabe: Evangelisches Missionswerk Hamburg), 75 S. Evang. Missionsverlag im christlichen Verlagshaus Stuttgart 1985. - Francis X. D'Sa, Gott, der Dreieine und der All-Ganze. Vorwort zur Begegnung z wischen Christentum und Hinduismus (Theologie interkulturell 2), 155 S. Patmos Düsseldorf 1987. - Ders., Das Recht, ein Mensch zu sein und die Pflicht, kosmisch zu bleiben, in: J. Hoffmann ( $\mathrm{Hg}$.), Begründung von Menschenrechten aus der Sicht unterschiedlicher Kulturen, $\mathrm{Vlg}$ für Interkulturelle Kommunikation Frankfurt a.M. 1991, 157-185. - Andreas Hoffmann-Richter, Abn Byung-Mu als Minjung-Theologe (MWF 24), 176 S. Gütersloher Vlg Gütersloh 1990. - Marianne Katoppo, mitleiden - mithandeln. Theologie einer asiatischen Frau (Compassionate and Free, Genf 1979; übers. von E. Frey. Erlanger Taschenbücher 56), $116 \mathrm{~S}$. Vlg der Ev.-Luth. Mission Erlangen 1981. - 
Sung-Hee Lee-Linke, Frauen gegen Konfuzius. Perspektiven einer asiatisch-feministischen Theologie, 224 S. Gütersloher Vlg Gütersloh 1991. - Aloysius Pieris, Liebe und Weisheit. Begegnung von Christentum und Buddhismus (aus dem Englischen übers. und hg. von W. Siepen), 203 S. Grünewald Mainz 1989. - George M. Soares-Prabbu (Hg.), Wir werden bei ihm wohnen. Das Johannesevangelium in indischer Deutung (aus dem Englischen übers. von U. Faymonville; Theologie der Dritten Welt 6), $184 \mathrm{~S}$. Herder Freiburg i.Br./Basel/ Wien 1984. - Choan-Seng Song, Theologie des Dritten Auges. Asiatische Spiritualität und christliche Theologie. Mit einem Nachwort von Wolfgang Gern (Third-Eye Theology: Theology in Formation in Asian Settings, Orbis Books Maryknoll, N. Y. 1979; übers. von P. Scherhans und A. Oesterle. ThÖ 19), 256 S. Vandenhoeck \& Ruprecht Göttingen 1989. - Ders., Theology from the Womb of Asia, 241 S. Orbis Books Maryknoll, N. Y. 1986. David Kwang-Sun Sub, The Korean Minjung in Christ, $198 \mathrm{~S}$. Commission on Theological Concerns - The Christian Conference of Asia, Hongkong 1991. - Katsumi Takizawa, Das Heil im Heute. Texte einer japanischen Theologie, hg. von T. Sundermeier (ThÖ 21), 220 S. Vandenhoeck \& Ruprecht Göttingen 1987. - Verlaß den Tempel. Antyodaya - Indischer Weg zur Befreiung, hg. von Felix Wilfred (aus dem Englischen übers. von U. Faymonville. Theologie der Dritten Welt 11), 208 S. Herder Freiburg i.Br./Basel/Wien 1988, darin u. a.: Sebastian Painadath, 51-68. - Seiichi Yagi, Die Front-Struktur als Brücke vom buddhistischen zum christlichen Denken (Ökumenische Existenz heute 3), 102 S. Kaiser, München 1988.

\section{Beispiele afrikanischer Theologie}

\subsection{Begegnung des Christentums mit afrikanischen Religionen und Kulturen}

Im folgenden werden Entwürfe von römisch-katholischen und evangelischen Theologen vorgestellt, die das Christentum in der Regel bereits im Kindesalter kennengelernt haben. Das Theologiestudium hat sie für mehrere Jahre ins europäische oder nordamerikanische Ausland geführt. Nach ihrer Rückkehr in die Heimat sind etliche von ihnen Priester, Lehrstuhlinhaber oder hohe kirchliche Würdenträger geworden (J.-M. Ela/Kamerun; F. E. Boulaga/Elfenbeinküste; O. Bimwenyi-Kweshi/Zaire; A. T. Sanon/Burkina Faso; G. M. Setiloane/Südafrika). Einige haben zeitweise in internationalen ökumenischen Organisationen mitgewirkt, mitunter sich auch im europäischen Ausland niedergelassen (A. A. Boesak, ehemaliger Präsident des Reformierten Weltbundes; M. A. Oduyoye, z. Zt. ÖRK/Genf; J. S. Mbiti, Pfarrer in Burgdorf/Schweiz; B. Bujo, Professor für Moraltheologie in Fribourg/Schweiz). Als Christen der zweiten oder dritten Generation haben sie zunächst die westliche Prägung afrikanischer Kirchen in sich aufgenommen, ehe sie danach im Verlauf ihres theologischen Werdegangs immer entschiedener davon Abstand nahmen. ${ }^{1}$ Eine Annäherung an die religiösen und kulturellen Traditionen Afrikas ging damit einher. Das radikale Umdenken bezüglich des Verhältnisses von Evangelium und afrikanischer Religion und Kultur verbindet die hier besprochenen Autoren über die Konfessionsgrenzen hinweg.

1 Im Fall von Boulaga hat sogar cine grundsätzliche Distanzierung vom Christentum stattgefunden. Nachdem er den Priesterstand und den Jesuitenorden verlassen hatte, nahm er einen Lehrstuhl für Philosophie an der staatlichen Universität der Elfenbeinküste an. 
Besonders eindrucksvoll hat sich die Umorientierung bei Oskar BimwenyiKweshi niedergeschlagen. Durch seine katholisch-theologische Erziehung hatte er gelernt, afrikanische Religion als Fremdreligion zu betrachten und den afrikanischen Riten mit negativen Vorurteilen zu begegnen. Erst die ${ }_{n} z w e i t e$ Bekehrung ", die derjenigen zum christlichen Glauben gefolgt ist, hat ihm die Augen geöffnet. Seitdem kann er, ohne sein Christsein aufzugeben, Afrikas kulturell-religiöses Erbe als etwas Eigenes akzeptieren. Was bei dem Orientierungswechsel in ihm vorgegangen ist, vergleicht er in seinem Buch "Alle Dinge erzählen von Gott ${ }^{\star 2}$ mit dem Erlebnis der beiden Jünger auf dem Weg nach Emmaus (Lk 24,13-35). In Gestalt eines Fremden stößt Jesus unterwegs zu den Jüngern. Sie erkennen ihn nicht, weil er ihnen anders als in der vertrauten Weise begegnet. Was ihre von Vorurteilen befangenen Augen "sehen", ist in der Deutung Bimwenyi-Kweshis ein Vertreter der Fremdreligion auf dem Weg in die fremd gewordene Heimat (Emmaus). Doch auf einmal geschieht das Wunder des Wieder-Erkennens in dem sich neigenden Tag: Nun wissen die Jünger, daß Jesus jene Fremdreligion und Fremdkultur angenommen hat, welche die westlich geprägten Christen in ihrer Verblendung glaubten ablehnen zu müssen. Damit hat Jesus selbst die Tür zu den Traditionen Afrikas aufgestoßen. Nun können ihm auch afrikanische Christen ohne Bedenken dorthin folgen, wohin er ihnen vorangegangen ist (10. 46. 49f. 172-177). ${ }^{3}$ Mit bewegenden Worten erzählt Anselme T. Sanon, katholischer Bischof in Burkina Faso, ein ähnliches Bekehrungserlebnis während seiner Studienzeit. „Und Christus offenbarte sich mir in der ergreifenden Darstellung des Kolosserbriefes (Kol 1,15-29) ... Mein spirituelles Leben als afrikanischer Seminarist stand von diesem unvergeßlichen Augenblick an im Einklang mit der Religion meiner Ahnen. " 4 Seitdem weiß er, daß er das Geheimnis Christi in der Sprache und Vorstellungswelt des afrikanischen Ahnenglaubens ausdrücken darf, denn zwischen beiden gibt es eine Entsprechung: Als Ebenbild Gottes macht Jesus Christus den unsichtbaren Gott sichtbar, so, wie in der Ahnenmaske das Unsichtbare durchscheint (88f). ${ }^{5}$ Inspiriert vom Hymnus des Kolosserbriefes und der Tradition der Sini, läßt er den afrikanischen Christushymnus mit den Worten beginnen (107):

"A hnenmaske,

mit dem Blick, der das unsichtbare Göttliche transparent macht, mit dem einzigartigen Antlitz des Häuptlings-Dieners, unzerreißbarer Faden, der uns mit dem Geschenk des Vaters verbindet ...“

${ }^{2}$ Die französischsprachige Dissertation umfaßt rund 600 Seiten; die deutsche Ausgabe der Arbeit ist stark gekürzt.

${ }^{3}$ Das Motiv der Emmaus-Erfahrung begegnet des öfteren auch bei anderen Autoren, so z. B. Sanon, Jesus, Meister der Initiation, in: Der schwarze Christus, 96.

A.a.O. 88.

${ }^{5}$ Zur Bedeutung der Ahnenmaske beim Initiationsritus gibt Sanon Erläuterungen in seinem Buch „Das Evangelium verwurzeln“, $28 f$. 
Sanon faßt die Aufgabe der Theologie in Afrika in den Worten zusammen: „Das Antlitz Christi sehen, sein afrikanisches Antlitz erkennen, das heißt, einen afrikanischen Namen für ihn zu finden" (93). Dies ist gewissermaßen auch der gemeinsame Leitsatz des Sammelbandes „Der schwarze Christus. Wege afrikanischer Christologie“, in dem Sanons Aufsatz „Jesus, Meister der Initiation“ abgedruckt ist. ${ }^{6}$ Die zehn Beiträge dokumentieren das Christuszeugnis katholischer Christen und Christinnen aus dem frankophonen Afrika.

Nach der „zweiten Bekehrung “ wird die Theologie nicht mehr in einem möglichst scharfen Kontrast zu den afrikanischen Religionen entfaltet; jetzt geht es vielmehr um eine Begegnung von Mitte zu Mitte. Man muß - wie der katholische Moraltheologe aus Zaire, Bénézet Bujo, es formuliert hat - „das Fundamentalste des Christentums und die tragenden Säulen der afrikanischen Tradition ... miteinander verflechten " "Afrikanische Theologie in ihrem gesellschaftlichen Kon-

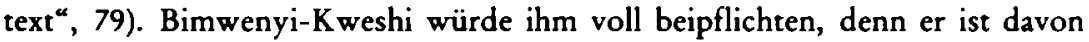
überzeugt, daß gerade dort, im Innersten der afrikanischen Tradition, Gott sich den Afrikanern zu erkennen gibt. Der brennende Dornbusch - Ort der Selbstoffenbarung Gottes - und der afrikanische Initiationsbusch schließen einander nicht aus. „Im brennenden Dornbusch zeigt sich das Feuer in, durch und dank diesem ,Busch', ohne ihn jedoch zu vertilgen, ohne ihn zu zerstören. ,Der im Dornbusch wohnt" (Dtn 33,16) läßt diesen bleiben, was er ist, während er sich selbst zugänglich macht durch den Busch und zugleich darin verborgen hält ${ }^{*}$ (174).

Der Initiationsbusch, die Verbindung zu den Lebend-Toten (Ahnen), der Anruf Gottes im Gebet und anderes mehr sind Zeugnisse von afrikanischer Spiritualität. In der ersten Phase der Missionierung Afrikas ist sie weitgehend verdrängt worden, bis die Erkenntnis zunahm, daß es für ein lebendiges afrikanisches Christentum berechtigt und sogar unverzichtbar ist, Elemente afrikanischer Spiritualität in die christliche Praxis einzubringen. Unter dem Titel ${ }_{n}$ Afrikanische Spiritualität und cbristlicher Glaube“ hat Mulago gwa Cikala M. elf Beiträge herausgegeben, welche anläßlich eines Kolloquiums in Kinshasa (1983) zu diesem Thema vorgetragen worden sind.

Nach übereinstimmender Auffassung der afrikanischen Inkulturationstheologie begegnet Gott dem afrikanischen Menschen im Zentrum seiner religiösen, kulturellen und spirituellen Identität. Eine Parallele zur Befreiungstheologie fällt auf, welche Gott in Christus im Zentrum des Leidens und der Krise findet und deswegen an die Kirche appelliert, sich dorthin zu begeben, zu den Menschen "draußen vor dem Tor" (Hebr 13,12f).

Im Bannkreis der neu entdeckten kulturell-religiösen Welt Afrikas blicken afrikanische Theologen überaus kritisch auf die Pionierzeit der Christianisierung ihres Kontinents zurück. Kein Autor geht mit der fremden Religionsform, die Afrika gewaltsam „übergestülpt ${ }^{\text {* }}$ worden sei, härter ins Gericht als $F$. Eboussi

${ }^{6}$ Ausführlich zu Sanons Buch (s. Anm. 5). 
Boulaga in seinem - leider nur auf französisch und englisch zugänglichen - Essay "Christianisme sans fétiche" Afrikas gegenüber in jeder Beziehung anmaßend und arrogant aufgetreten. Die Idee der göttlichen Offenbarung in der Geschichte habe es dazu benutzt, einen absoluten Wahrheitsanspruch geltend zu machen und das Fundament der afrikanischen Religion, den Mythos, als primitive und heidnische Auflehnung gegen Gott bloßzustellen (1-56). Kolonisation, Missionierung und Modernisierung haben aus der Sicht von Bujo das Gesamtgefüge der afrikanischen Gesellschaft aus dem Gleichgewicht gebracht (Afrikanische Theologie, 43ff). Im Verlauf dieses Prozesses seien die "Befreiungsdimensionen " der vorkolonialen und vorchristlichen Tradition Afrikas zerstört worden (21ff). Die methodistische Theologin Mercy A. Oduyoye aus Ghana setzt sich in ihrem Buch "Wir selber haben ihn gehört" mit der neueren Missionsgeschichte auseinander (49-70). Den Experten für afrikanische Kirchengeschichte mag ihre Darstellung, ähnlich wie diejenige von Boulaga, zu einseitig an den abschreckenden Beispielen der Seelenfängerei orientiert sein. Doch wen kann es wundern, daß gerade die schmerzlichsten Demütigungen während der Missionierung Afrikas in der dortigen Bevölkerung besonders nachhaltige Eindrücke hinterlassen haben? Die dunklen Seiten jener Epoche gehören wohl noch für geraume Zeit zu den vorrangigen Aufgaben afrikanischer (Kirchen-) Geschichtsschreibung.

Zunehmend richten Theologen und Theologinnen aus Schwarzafrika ihre Kritik auch an die afrikanischen Kirchen der nachkolonialen Zeit. Boulaga schreibt dem afrikanischen „Mittelklasse-Christentum “ die Verantwortung dafür zu, daß es das christlich-abendländische Weltbild gedankenlos nachahmt (57ff). JeanMarc Ela, katholischer Theologe und Soziologe, nimmt kein Blatt vor den Mund, wenn er die hierarchischen Strukturen der katholischen Kirche in Kamerun aufzeigt. Mit der Alleinherrschaft des Klerus, dem tridentinischen Priestermodell, der Ersatzfunktion von Laienmitarbeitern und den zur Unselbständigkeit verurteilten Gemeinden bleibe die römisch-katholische Kirche in Afrika ein Fremdkörper („Mein Glaube als Afrikaner“, 70ff). Ela spricht vom „zwiespältigen Abenteuer“, das für die Mehrheit der schwarzafrikanischen Christen mit dem Eintritt in die christliche Kirche beginne. In Zaire wird dieses Thema mit den Worten besungen: „Ach, ihr unglücklichen Christen! Morgens bei der Messe, abends beim Wahrsager. In der Tasche ein Amulett. Am Hals ein Skapulier! ${ }^{\alpha}$ (154). Das Spottlied auf die afrikanischen Christen läßt deren verdrängte Sehnsucht nach den kulturellen und religiösen Wurzeln ihrer Heimat erahnen. Ela deutet das blühende Sektenwesen in Afrika als Versuch, den Zwiespalt des afrikanischen Christen zu überwinden.

7 Die Seitenangaben beziehen sich auf die englische Ausgabe. Eine deutschsprachige Zusammenfassung findet sich bei John Parratt, Theologiegeschichte der Dritten Welt - Afrika, München 1991, 151-172; vgl. außerdem Ulrike Link-Wieczorek, Reden von Gott in Afrika und Asien. Darstellung und Interpretation afrikanischer Theologie im Vergleich mit der koreanischen Minjung-Theologie (FSÖTh 60), Göttingen 1989, 184-199. 
Das führt uns zur Frage nach dem Verhältnis von Inkulturation und Synkretismus. Wie läßt sich die "Inkarnation des Evangeliums in Afrika“ (Ela, 154) von einer undifferenzierten Gleichsetzung des Evangeliums mit den afrikanischen Traditionen unterscheiden? In der besprochenen Literatur wird an der Notwendigkeit, zwischen legitimer Inkulturation und unzulässiger Religionsvermischung zu unterscheiden, durchwegs festgehalten. Die Afrikaner bestehen freilich darauf, die Grenze anders zu ziehen, als es in der theologischen Schulbildung im Westen üblich ist. Von einem Konsens über den richtigen Grenzverlauf sind sie allerdings weit entfernt. Ela rechnet beispielsweise die Afrikanischen Unabhängigen Kirchen pauschal den Sekten zu, wogegen Boulaga einen lebendigen Ausdruck christlichen Glaubens einzig diesen Kirchen zubilligt (63ff).

Die Verhältnisbestimmung von Inkulturation und Synkretismus bedarf gewiß noch weiterer Klärung. Hierbei schlägt sich im übrigen die konfessionelle Prägung der Autoren nieder. Oduyoye orientiert sich bei ihrer Suche nach neuen Wegen der Theologie am Diskussionsprozeß innerhalb des Ökumenischen Rates der Kirchen. Bei den Katholiken fällt auf, daß sie sich ohne die Vergewisserung ihrer Treue zur römischen Tradition nicht auf den interreligiösen und interkulturellen Dialog einlassen könnten. Im II. Vatikanischen Konzil erkennen sie übereinstimmend die Grundlage für dieses Wagnis. Gegen neuere Tendenzen des Heiligen Stuhls, hinter das II. Vatikanum zurückzufallen, läßt Ela Papst Paul VI. und selbst Johannes Paul II. zu Wort kommen, wo irgend es ihm vertretbar erscheint. „Die Afrikanisierung ist eure Aufgabe“ (Johannes Paul II. zu den Bischöfen von Zaire); „Ein Bruch zwischen dem Evangelium und der Kultur wäre ein Drama“ (ders. 1985 in Kamerun). ${ }^{8}$

\subsection{Bibel und christlicher Glaube in afrikanischer Deutung}

In der afrikanischen Christenheit spielt die Bibel eine zentrale Rolle. Ausländische Missionare haben mit der Übersetzung der Schrift in viele afrikanische Sprachen eine wichtige Voraussetzung dafür geschaffen. Noch entscheidender dürfte freilich die Evangelisierung durch die Afrikaner selbst gewesen sein, welche die Bibel unter der afrikanischen Bevölkerung bekannt gemacht haben und es bis heute auch weiterhin tun. Zu diesem Ergebnis kommt John S. Mbiti in seinen Untersuchungen zu „Bibel und Theologie im afrikanischen Christentum“. Das Bibelstudium in der Muttersprache habe afrikanische Christen von der Kontrolle durch ausländische Missionare geistig unabhängig gemacht, wie denn auch die Afrikanischen Unabhängigen Kirchen weitgehend auf die Bibelübersetzungen zurückzuführen seien (36f). Nach Beobachtungen Mbitis liegen die Parallelen zwischen der religiösen Welt Afrikas und der Welt der Bibel für viele Gläubige bereits auf der Hand (22). Wenn dies bereits für Christen ohne theologische Ausbildung zutrifft, ist die Frage naheliegend, wie sich die Verwendung der Bibel in den theologischen Entwürfen aus Afrika niederschlägt. Von einer zusammenfas-

${ }^{8}$ Zit. bei Ela, Mein Glaube als Afrikaner, 160; ferner 35. $128 f$. 
senden Bemerkung abgesehen geht Mbiti darauf nicht ein. Sein Schweigen bestätigt indirekt, was John Parratt vor kurzem festgestellt hat: „Auf der Ebene der konsequenten Bibelwissenschaft gibt es aber einen deutlichen Mangel an fundierten Beiträgen (sc. von afrikanischen Theologen, C. L.). ${ }^{49}$

Dies mag zutreffen, beeinträchtigt indessen nicht die Bedeutung der Bibel als Orientierungshilfe im Leben afrikanischer Christen und Gemeinden - z. B. in Südafrika. Davon zeugen die Predigten des reformierten Befreiungstheologen $A l$ lan A. Boesak zwischen 1980 und 1986. In all den Jahren der Greueltaten an Unschuldigen, der Ausweglosigkeit schwarzer und farbiger Menschen - aber auch des Widerstandes gegen den Unrechtsstaat -, hat er seiner Gemeinde die Apokalypse des Johannes als Zeugnis für Trost und Protest ausgelegt („Schreibe dem Engel Südafrikas“). Boesak zweifelt nicht an der ngegenwartsbezogenen geschichtlichen Bedeutung “ der Apokalypse. „Deshalb ist die Offenbarung für uns heute so wichtig ..., weil wir mit tiefem Staunen erkennen, wie zutreffend und genau Johannes über seine Zeit schreibt und auch die Zeit darstellt, in der wir leben " (26). Den Gemeindepfarrer und Prediger Boesak lernt man auch durch die Bibelmeditationen kennen, die in seinem Büchlein „Gerechtigkeit erhöht ein

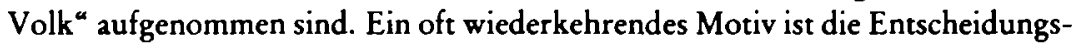
schwäche der zwischen Anpassung und Widerstand hin und her schwankenden Kirche. „Wir wissen genau, was wir tun sollten, aber uns fehlt der Mut, es wirklich anzugreifen ... Und deshalb halten wir ununterbrochen Ausschau nach Kompromissen“ (105). Genauso hat sich Ruben, der älteste Bruder von Josef, verhalten (Gen 37,21f). Als es darum geht, den lästigen Lieblingssohn des Vaters zu beseitigen, entscheidet sich Ruben für die „klägliche Rolle des , verantwortungsbewußten' Bruders. Er möchte beide Seiten bei Laune halten: möchte genug tun, um sein Gewissen zu beruhigen, aber nicht genug, das Leben seines Bruders zu retten" (ebd.). Als "Ethik à la Ruben“ charakterisiert Boesak in seiner Predigt die Strategie, durch die Rede von der „Verantwortung für alle Seiten“ dem Widerstand gegen das Böse aus dem Weg zu gehen (102-109).

Was sind die Merkmale afrikanischer Theologie? Antwort darauf geben am ehesten die Arbeiten zu einzelnen dogmatischen Topoi - etwa zur Gotteslehre, Christologie, Pneumatologie und Ekklesiologie. Was aber sind die Voraussetzungen afrikanischer Theologie? Selten wird die Frage aufgegriffen. Eine Ausnahme ist Bimwenyi-Kweshi, der zu klären versucht, warum theologische Aussagen in kulturell und religiös verschiedenen Deutungen nicht nur möglich, sondern unumgänglich sind. Im Mittelpunkt seiner "Grundlegung afrikanischer Theologie“ (Untertitel der deutschen Ausgabe) steht die These von der zweipoligen Struktur der Offenbarung. Weil Gott sich in vielen Sprachen der Menschheit kundtut, ist die Offenbarung ntheisch" und nandrisch" zugleich (56ff). Ausführ-

9 Parratt, a.a.O., 90. Er räumt freilich ein: „Mbitis Untersuchung, New Testament Eschatology' und verschiedene Abhandlungen von Autoren wie Sawyerr, Dickson und Pobee stechen hervor, weil sie das Bibelstudium ernstnehmen " (ebd.). 
lich verweilt Bimwenyi-Kweshi auf der afrikanischen Form des andrischen Pols und zeigt auf, was vor der Berührung mit dem Christentum in der afrikanischen Sprach- und Vorstellungswelt von Gottes Wirklichkeit sichtbar geworden ist: Gott der Unbegreiflich-Andere, der Eine, der Immer-schon-Dagewesene, der Abgründige, Mächtige, Allgegenwärtige - diese und viele andere Beispiele afrikanischer Gotteserkenntnis illustriert der Autor anhand von mündlichen Überlieferungen verschiedener Gegenden Afrikas. Für ihn steht fest, daß Afrika von Gott bereits wußte, längst bevor es das Christentum kennenlernte. Deshalb, so sein Ergebnis, müssen die afrikanischen Erkenntnisse in die christliche Theologie einfließen als notwendige Ergänzung und Bereicherung des Glaubens.

Bimwenyi-Kweshi erweckt den Eindruck, die Beispiele afrikanischer Gotteserkenntnis nach dem Prinzip der Entsprechung auszuwählen. Nur was mit der jüdisch-christlichen Tradition vereinbar ist, nimmt er auf. Anders der südafrikanische Theologe Gabriel M. Setiloane (Methodist), den die Gleichsetzung von afrikanischen und christlich-abendländischen Gottesvorstellungen nicht überzeugt ("Der Gott meiner Väter und mein Gott ${ }^{4}$ ). Zwar bezeugt auch er wie Bimwenyi-Kweshi, daß der Gott des Alten und Neuen Testaments kein anderer sei als derjenige, der sich den Afrikanern beispielsweise als Modimo, Thixo, Lesa offenbart habe (53). Aber er wirft den Missionaren vor, die christliche Botschaft dem afrikanischen Wissen um Gott aufgepfropft und dabei nicht erkannt zu haben, daß die Afrikaner Gott trotzdem weiterhin in ihren afrikanischen Kategorien begriffen (49). Modimo (Gott), wie ihn die Sotho-Tswana kennen, ist eher ein Es als eine Person - schon gar nicht ein Vater; Modimo ist eher „unten “ als „droben im Himmel“; er ist Energie, die Handeln in Gang setzt und Wechselwirkungen auslöst (45ff). Setiloane ist gewiß, daß gerade der Kontrastreichtum menschlicher Gotteserkenntnis zur Geltung gebracht werden muß. Darum gehe es der afrikanischen Theologie, die in der Auseinandersetzung mit abendländischen Verstehensweisen und Einsichten dennoch beanspruche, „ganz und gar christlich zu sein" (50). Neben der Gotteslehre ist die Christologie der wichtigste Ausgangspunkt afrikanischer Theologie. Auf der Suche nach dem afrikanischen Antlitz wird Christus als Häuptling (François Kabasélé), Ahne (Charles Nyami$\mathrm{ti}^{10}$, Bénézet Bujo) oder Initiationsmeister (Anselme T. Sanon) interpretiert. Die in "Der schwarze Christus“ zusammengefaßten Beiträge rücken wiederum hauptsächlich die Kontinuität $z$ wischen afrikanischer Tradition und christlichem Glauben in den Vordergrund, indem sie an die positiv bewerteten Seiten des afrikanischen Häuptlings, Ahnen und Initiationsmeisters anknüpfen. "

Bei Sanon wird zudem eine weitere Voraussetzung für die „Glaubenserschlie-

${ }^{10}$ C. Nyamiti, Christ as Our Ancestor. Christology from an African Perspective, Gweru/Zimbabwe 1984. Vgl. dazu T. Sundermeier, Fremde Theologien, in: EvTh 50, 1990, 524-534.

11 Kabasélé, Christus als Häuptling, in: Der schwarze Christus, 57-72; ders., Christus als Ahne und Ältester, a.a.O., 73-86; Sanon, Jesus, Meister der Initiation, a. a.O. 87-107. 
Bung im Raum afrikanischer Stammesinitiationen " erkennbar. In seinem Buch "Das Evangelium verwurzeln " gelingt es ihm mühelos, die Initiationsriten auf Christus und die Getauften (Initiierten) zu übertragen, indem er von vielen Konkretisierungen dieser Riten abstrahiert und nur bestimmte Grundstrukturen herausarbeitet: die Initiation als Symbol für Tod und Neugeborenwerden und als Zeichen der Verbundenheit mit den Lebend-Toten, die Bedeutung des (schmerzlich geprüften) Körpers für die Wissensaneignung, der Sinn für das Geheimnis (9f.37ff). Bujo wiederum kann den afrikanischen Ahnen auf Christus übertragen, weil er von den dunklen Seiten des Ahnenglaubens absieht und darüber hinaus Christus als Proto-Ahn über die gesamte Ahnenwelt erhebt (Afrikanische Theologie, $79 \mathrm{ff}) .^{12}$

Müßte die Diskontinuität zwischen afrikanischer Glaubenswelt und Christusglauben nicht auch thematisiert werden, wenn das Antlitz Christi eine afrikanische Gestalt annehmen soll? Die Frage beschäftigt Cécé Kolié, wenn er Jesus zum afrikanischen Heiler in Beziheung setzt ("Jesus - Heiler?", in: Der schwarze Christus, 108-137). Im Unterschied zu manchen Inkulturationstheologen bemüht er sich um ein differenziertes Bild von der Gestalt des afrikanischen Heilers im traditionellen und im nachkolonialen, christianisierten Afrika. Dementsprechend ist er vorsichtig, Jesus auf die Gestalt des Heilers zu übertragen. Skeptisch äußert er sich auch über die Tendenz, Christus in der Liturgie als einzigartigen Initiationsmeister oder Häuptling der Häuptlinge zu feiern. Bezogen auf ähnliche Versuche in der afrikanischen Theologie fragt er sich, „ob unser theologischer Kulturalismus heute, wo die tagtäglichen Probleme in Afrika Hunger, Diktatur, Arbeitslosigkeit, Emigration, Korruption, Veruntreuung öffentlicher Gelder usw. heißen, nicht ein Relikt aus der politischen Zeit der Negritude ist “ (137).

\subsection{Inkulturation und Befreiung}

Das Zitat von Kolié zeigt an, daß das Verhältnis von Inkulturation und Befreiung dringend einer Klärung bedarf. In den sechziger und siebziger Jahren nahm die ${ }_{n}$ african theology" in Schwarzafrika einseitig auf die kulturelle Vergangenheit Bezug, während sich im Südlichen Afrika die „black theology“ hauptsächlich auf die politische und wirtschaftliche Krisensituation der Gegenwart konzentrierte. ${ }^{13}$ Heute werden in den theologischen Entwürfen aus ganz Afrika Inkulturation und Befreiung allgemein als zwei gleichgewichtige, miteinander zu verbindende Anliegen bezeichnet. Gleichwohl wird der Akzent weiterhin entweder auf den einen oder den anderen Aspekt gelegt; die inhaltliche Verbindung von beidem gelingt zudem nur selten. Bimwenyi-Kweshi beispielsweise registriert die „bruta-

${ }^{12}$ Nach den Implikationen der Proto-Ahn-Christologie für die Ethik fragt Bujo in mehreren Beiträgen seines Buches „African Christian Morality at the Age of Inculturation“.

${ }^{13}$ Dazu Parratt, a.a.O., 54ff. Der Austausch zwischen Dritte-Welt-Theologen im Rahmen der EATWOT-Konferenzen hat zur Überwindung der Aufspaltung in "african ${ }^{\alpha}$ und „black theology“ beigetragen. Zur EATWOT vgl. V. Küster in diesem Heft. 
len Veränderungen" im politischen und wirtschaftlichen Bereich, wendet sich dann aber doch nur den religiösen und kulturellen Wurzeln Afrikas zu. „Hat die ,Modernität' die ,Afrikanität' verschlungen?“ (33). Er verneint es und meint, trotz der dramatischen gesellschaftlichen Umwälzungen südlich der Sahara sei das im Verborgenen weiterlebende traditionelle Afrika nach wie vor der ausschlaggebende Faktor, mit dem sich Kirche und Theologie auseinandersetzen müssen (33ff).

Von allen Theologen aus Schwarzafrika hat sich Ela am stärksten darum bemüht, die befreiungstheologische Perspektive der „black theology“ aufzunehmen. Er blendet die Inkulturationsproblematik nicht aus, verlagert aber das Gewicht eindeutig auf die Befreiungstheologie und distanziert sich von Entwürfen, die nur für das kulturelle Erbe Afrikas Interesse zeigen. „Der Rhythmus der Tam-Tams und der Marimbas in den Kirchen Afrikas darf uns nicht blind und taub machen für die Bedrohungen durch die 'Nahrungsmittelwaffe', denen unsere unter der Diktatur des Erdnuß-, Kakao- und Baumwollanbaus stehende Landbevölkerung ausgesetzt ist" (163). Die Befreiung der Unterdrückten ist nach Ela die wesentliche Voraussetzung jeder echten Inkulturation. Er begnügt sich nicht damit, die Ursachen für die katastrophalen Lebensverhältnisse in Kamerun ausschließlich im westlichen Ausland zu suchen. Für Korruption, Menschenrechtsverletzungen, die "Strategie des Hungers und der Sklaverei“ (109), für die Diskrepanz zwischen parasitärer Beamtenschaft und Massenarmut macht er überwiegend die einheimischen Eliten verantwortich, die er „Kinder der WeiBen " nennt (131f.138). Ela erinnert an das Widerstandspotential, das in der afrikanischen Kultur angelegt ist und zu neuem Leben erweckt werden sollte. „Der Widerstand ist im Gedächtnis des traditionellen Afrika fest verankert " (113; ferner 10f). Aus der biblischen und der afrikanischen Befreiungstradition heraus formulier er den „Appell zur radikalen Infragestellung aller Unrechtsstruktu-

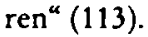

„Über Schwarze Theologie und Befreiungstheologie ist in Südafrika schon viel gesagt und geschrieben worden, über Afrikanische Theologie hingegen wenig“, schreibt Setiloane und versteht seinen eigenen Beitrag als „Afrikanische Theologie im Kontext der Apartheid" (19). Von ein paar Andeutungen am Schluß des Büchleins (103ff) abgesehen, kommt der Bezug seines Entwurfs zur südafrikanischen Gegenwart freilich nicht in den Blick. Umgekehrt schenken andere südafrikanische Theologen aus dem oppositionellen Spektrum ihre Aufmerksamkeit nahezu ausschließlich den Folgen der Apartheid für die Bevölkerung. Bisher hat sich die theologische Besinnung über den kirchlichen und gesellschaftlichen Widerstand gegen das Apartheidsystem vornehmlich im Umkreis dreier Institutionen herauskristallisiert: Bis 1977 war es das von Ch. F. Beyers Naudé geleitete Christliche Institut, danach der Südafrikanische Kirchenrat und seit 1985 parallel dazu das Institut für Kontextuelle Theologie. Einen guten Einblick in die Arbeit des Südafrikanischen Kirchenrates vermittelt das Buch ${ }_{n}$ Hoffnung in der Krise", das zum 65. Geburtstag von Wolfram Kistner, einem langjährigen Mitarbeiter des 
Kirchenrates, herausgebracht worden ist (Hammer Wuppertal 1988). Es enthält wichtige Beiträge des Geehrten sowie Texte seiner Mitarbeiter und Freunde aus dem In- und Ausland. Kistners theologische Arbeit, die in den achtziger Jahren den Kirchenrat geprägt hat, ist von der Erfahrung der Gerechtigkeit und Versöhnung bestimmt. Zur Gerechtigkeit rufen seine Bibelmeditationen und Projektberichte auf aus der Einsicht in Gottes Solidarität mit den Armen. Zugleich versteht er die Gerechrigkeit in enger Verbindung mit der Versöhnung aufgrund der Einsicht in Gottes Solidarität mit den Sündern. Aus der Option für die Armen folgt die Notwendigkeit, für die Armen Partei zu ergreifen, und aus der Solidarität mit den Sündern die Notwendigkeit, für das Wohl aller einzutreten. Kistner würde Boesak darin zustimmen, daß man der „kläglichen Rolle des 'verantwortungsbewußten 'Bruders" (s. o.) nicht das Wort reden darf. Sein eigener Ansatz zeigt meines Erachtens auf, wie kirchliche Verantwortung angesichts einer unrechtmäBigen staatlichen Ordnung zu begreifen wäre.

Das Kairos-Dokument gab 1985 den Anstoß zu einer heißen Diskussion um die politische Krise in Südafrika und die verschiedenen Optionen der Kirche, darauf zu reagieren. ${ }^{14}$ Die Anregung dazu kam aus dem Institut für Kontextuelle Theologie; an der Ausformulierung waren aber - ein Novum in Südafrika - viele Christen aller Hautfarben aus allen Teilen des Landes, verschiedenen Denominationen und Bevölkerungsschichten beteiligt. Dem Institut für Kontextuelle Theologie gehört Albert Nolan, katholischer Theologe und Mitglied des Dominikanerordens, an, der das Institut mitbegründet und aufgebaut hat. Er war maßgeblich am Zustandekommen des Kairos-Dokuments beteiligt, in dessen Geist er das Buch "Gott in Südafrika" geschrieben hat. Nolan ist der Kontextuellen Theologie verpflichtet, die an die "black theology" der siebziger Jahre anknüpft und sie auf der Grundlage der Freiheitscharta von 1955 weiterentwickelt (22). Er hat das Buch unter dem Eindruck des blutig niedergeschlagenen Sowetoaufstandes von 1976, der Verfassung von 1983, des Ausnahmezustandes Mitte der achtziger Jahre geschrieben. Damals war die Hoffnung auf den „Tag der Befreiung“ und die Zeit danach ungebrochen (181. 216). Heute liest sich das Buch wie aus einer Zeit, die der Vergangenheit angehört. In den Barackensiedlungen am Rande der Townships, die dramatisch weiterwachsen, ist die Hoffnung vielfach der Resignation gewichen. Die Pfeiler des "Systems" sen (110. 113. 224), sind eingestürzt. Gekommen ist freilich nicht der "Tag der Befreiung", sondern ein für die einfache Bevölkerung schwer durchschaubarer und schmerzlicher Prozeß des Übergangs. Heute wagen Oppositionelle nicht mehr ohne weiteres, zwischen Opfern und System so klar zu unterscheiden, wie Nolan es tut, wenn er schreibt: „Die Opfer der Sünde sind außerhalb des Zyklus der Sünde" (124). Die jüngste Zäsur in Südafrikas Entwicklung verlangt von Kirchen und Theologie, ihre Aufgaben im Übergang zu einer gerechteren Gesell-

${ }^{14}$ Das Kairos-Dokument und die Diskussion um dasselbe sind abgedruckt in: Hinz/ Kürschner-Pelkmann, Christen im Widerstand. 
schaftsordnung neu zu klären und dabei vielleicht auch zu fragen, wie der $\mathrm{Zu}$ sammenhang von Befreiung und Inkulturation in der neuen Situation zu bestimmen wäre.

Es ist kein Zufall, daß es afrikanischen Theologinnen leichter fällt als Theologen, Inkulturation und Befreiung als Ganzes zu behandeln. Afrikanerinnen haben einen doppelten $Z$ wiespalt zu überwinden: jenen zwischen westlicher Welt und afrikanischer Tradition und jenen zwischen männlicher Dominanz (in beiden Welten) und weiblichem Selbstverständnis. Mercy $A$. Oduyoye hat sich lange Zeit mit den mehrfach überlagerten Konflikten afrikanischer Christinnen befaßt. In ihrem Buch entfaltet sie die These, der Feminismus sei eine unverzichtbare Voraussetzung für eine christliche Anthropologie (174-200). Sie deckt ein weites Problemfeld auf, das in den Beiträgen der hier besprochenen männlichen Autoren bestenfalls ganz am Rande gestreift, meistens aber ganz ausgeblendet wird, obwohl kaum etwas stärker kulturell und religiös geprägt sein dürfte als das Menschenbild und die Beziehung zwischen den Geschlechtern. Oduyoye steht in einer größeren Distanz zu den afrikanischen Traditionen als die übrigen Autoren und ist daher auch eher in der Lage, die Inkulturation an bestimmte Kriterien nicht zuletzt die Befreiung - zu binden. Orientierungspunkt für eine Neuordnung der zwischenmenschlichen Beziehungen in Ehe, Familie und Gesellschaft ist für sie die Dreifaltigkeit, weil "keine der drei göttlichen Personen einer anderen untergeordnet wird und sie dennoch zusammen als der eine, einzige Gott der Welt gegenüber auftreten. So ist uns Gott selbst in seinem Sein Vorbild für die integrale Ganzheit und Unverletztheit jeder Person im Gesamt gesellschaftlicher Bezüge“ (198).

\section{Beispiele asiatischer Theologie}

2.1. Begegnung des Christentums mit asiatischen Religionen und Kulturen

Von der neueren theologischen Literatur Asiens greife ich zunächst die Werke von vier Autoren heraus, für die der Dialog zwischen Christentum und asiatischer Religion zu einer Schlüsselfrage - wenn nicht zum Lebensinhalt schlechthin - geworden ist: Seiichi Yagi (Japan), Katsumi Takizawa (Japan), Aloysius Pieris (Sri Lanka) und Francis X. D'Sa (Indien). Ihnen ist, erstens, die Verankerung in zwei Religionen bzw. Kulturkreisen gemeinsam. Sie verkörpern im besten Sinn des Wortes eine ninterreligiöse Existenz ${ }^{\alpha 15}$, d. h. sie führen den interreligiösen Dialog nicht nur mit Gesprächspartnern, sondern in ihnen selbst begegnen sich zwei Religionen und Kulturkreise. Zweitens erreicht der interreligiöse Dialog bei den vier Autoren "eine Tiefe, wie man sie sonst kaum findet ${ }^{\text {" }}{ }^{16}$. Gerade ihrer Beschränkung auf zwei Religionen (Christentum und Buddhismus oder Hinduis-

is So wird u. a. Takizawa charakterisiert in: Religionen, Religiosität und christlicher Glaube: Eine Studie, hg. im Auftrag der VELKD und der Arnoldshainer Konferenz, Gütersloher Vlg Gütersloh 1991, 74-76.

${ }^{16}$ So Sundermeier in seiner Einführung zu Takizawa, in: Takizawa, Das Heil im Heute, 21. 
mus) - und innerhalb derselben wiederum auf einzelne, zentrale Aspekte - ist es $z u$ verdanken, daß der Dialog in jener außergewöhnlichen Tiefe und fruchtbaren Beziehungsvielfalt gelingt. Den Dialog begreifen sie, drittens, als eine Begegnung auf mehreren Ebenen, einschließlich des akademischen Diskurses, der Meditation, Spiritualität und Aktion. So wie sich ein befreiungstheologischer Ansatz häufig von der Biographie eines Autors oder einer Autorin her erschließt, ist auch der Werdegang der vier genannten Theologen ein Schlüssel zu ihrem Verständnis der interreligiösen Verständigung.

Seiichi Yagi (geb. 1932), aufgewachsen in einer protestantisch geprägten christlichen Familie in Yokohama, hat erst in einer späten Phase seines wissenschaftlichen Werdegangs einen Zugang zum Buddhismus gefunden. Der christliche Theologe und Philosoph schildert sein Erlebnis des "Erwachens" (im Sinn des Zen-Buddhismus) während eines Studienaufenthaltes in Deutschland als "zweite Bekehrung ", die seinem Denken eine neue Richtung gegeben hat. "Seither weiß er sich dem Ziel verpflichtet, eine Brücke zwischen Christentum und Buddhismus zu schlagen. Dies gelingt ihm in seinem kleinen Buch „Die Front-Struktur als Brücke vom buddhistischen zum christlichen Denken “. Beide Religionen - so seine Hauptthese - sind auf den Dialog miteinander angewiesen, weil sich die Wahrheit nicht allein von einer Religion her erschließen läßt. „Wahrheit gibt es nur gemeinsam. ${ }^{\alpha 18}$ Yagi unterscheidet sich in seinem Bemühen um die Begegnung von Christentum und Buddhismus von den japanischen Schultheologen. Sein großer japanischer Leserkreis besteht mehrheitlich aus Nichtchristen, die seine Bücher lesen, weil dieselben ,ihrem Bedürfnis nach einer Hineinnahme Christi in die eigene religiöse Lebenswelt . . entgegenkommen ${ }^{\star 19}$.

Wie Yagi ist auch Katsumi Takizawa (1909-1984) ein unorthodoxer Theologe und Brückenbauer. Als Professor für europäische Philosophie und Ethik hat er von 1947 bis 1971 an der staatlichen Kyushu-Universität in Fukuoka gelehrt. Ehe er 1933 in Bonn durch Karl Barth mit der christlichen Theologie in Berührung kam, hatte er sich von Kitaro Nishida, dem Zen-Philosophen und Begründer der Kyoto-Schule, in den Buddhismus einführen lassen. Von beiden Lehrern tief beeindruckt, widmete Takizawa fortan einen wichtigen Teil seiner Forschungs- und Lehrtätigkeit der Verbindung zwischen christlichem und buddhistischem Denken. Am interreligiösen Dialog interessierte ihn nicht der phänomenologische Vergleich, sondern der Versuch, die ontologischen Strukturen des christlichen und buddhistischen Denkens aufzuweisen. ${ }^{20}$

Der in Sri Lanka lebende Theologe und Jesuit Aloysius Pieris (geb. 1934) hat

$17 \mathrm{Zu}$ Yagis Werdegang vgl. U. Luz in seiner hilfreichen Einführung, in: Yagi, Die FrontStruktur, 7-19; ebenso U. Luz, Zwischen Christentum und Buddhismus: Seiichi Yagi, Japan, in: Hans Waldenfels (Hg.), Theologen der Dritten Welt, München 1982, 161-178.

${ }_{18}$ Einführung von Luz, in: Yagi, Die Front-Struktur, 18.

19 Luz, a.a.O. 10.

$20 \mathrm{Vgl}$. etwa den Beitrag von Yagi ",Rechtfertigung* im Buddhismus und im Christentuın “, in: ders., Das Heil im Heute, 181-196. 
nach Abschluß seines Theologie- und Philosophiestudiums in Indien und Italien als erster Christ in Buddhistischer Philosophie promoviert. Das von ihm in Sri Lanka gegründete christlich-buddhistische Dialog- und Begegnungszentrum ist ein konkreter Ausdruck dafür, daß er neben dem interreligiösen Diskurs mehr noch die communio in sacris sucht. Sein Aufsatzband "Liebe und Weisheit" spiegelt die Begegnung von buddhistischen und christlichen Mönchsgemeinschaften wider - von Menschen also, „die ihrer religiösen Inbrunst den umfassendsten und authentischsten Ausdruck verleihen" (145).

Auch der indische Theologe und Philosoph Francis X. D'Sa (geb. 1936) gehört der Gesellschaft Jesu an. Der in Poona (Indien) wirkende Professor für indische Religionen und Philosophie ist an der Entwicklung von interkulturellen Verständigungsmöglichkeiten interessiert. In „Gott, der Dreieine und der All-Ganze klärt er die methodischen Voraussetzungen eines Dialogs zwischen Christentum und Hinduismus. Wie D'Sa den Dialog praktiziert, hat er 1990 auf einem Symposium in Frankfurt a.M. deutlich gemacht. Auf die Frage eines taiwanischen Ordensbruders, ob er nun Christ oder Hindu sei, gab D'Sa zur Antwort: "Ich bin Christ und Hindu. “ Im folgenden beschränke ich mich jeweils auf einen zentralen Gedanken der vier genannten Werke.

Yagi beschäftigt die wechselseitige Vermitteltheit alles Seienden. Im Bild zweier durch eine Wand getrennter Zimmer veranschaulicht er das Gemeinte: Die Wand eines Zimmers ist zugleich die „Front" des Nachbarzimmers. Auf dieselbe "Front-Struktur" stößt man seiner Meinung nach bei jedem Seienden, denn kein Ding könne für sich existieren, sondern verdanke seine Existenz der Partizipation an anderen Dingen. Für Yagi erhellt sich durch das Bild von der Front-Struktur nicht nur die Beziehung zwischen Christentum und Buddhismus (das Christentum als Front der Wahrheit für den Buddhismus und letzterer als Front der Wahrheit für das Christentum), sondern er findet darin auch einen Schlüssel zum Verständnis zentraler christlicher und buddhistischer $W$ ahrheiten. Illustrativ dafür ist Yagis Auslegung des biblischen Wortes in Gal 2,20 (Ich lebe, aber nicht mehr ich, sondern Christus in mir). Solange das Ich (Ego) sich allein aus sich selbst heraus verstehen will und sich damit verabsolutiert, verliert es sich und verfehlt die Wahrheit, nach der es sucht. Der Mensch aber, der sein Ego ganz losläßt, empfängt sich auf neue Weise wieder im Selbst (Christus in mir). Eine ähnliche Gedankenfigur begegnet laut Yagi im Amidismus: Das Ego verwandelt sich dann in das Selbst, wenn es vorbehaltlos Ausdruck eines anderen, nämlich Amidas, wird.

Der von Theo Sundermeier herausgegebene und eingeleitete Band "Das Heil im Heute“ enthält mehrere Schriften von Takizawa sowie einen Briefwechsel des Autors mit J. Moltmann und H. Gollwitzer. „Für ewig geschieden/doch keinen Augenblick getrennt/den ganzen Tag zusammen/doch keinen Augenblick in eins" - das ist nach Sundermeier der Schlüsselsatz der Theologie Takizawas (18). Auf das Gott-Mensch-Verhältnis angewendet bedeutet das Paradox, daß der von seinem Geschöpf radikal verschiedene Gott gerade in dieser Distanz ewig bei sei- 
nem Geschöpf ist. Den "Gott mit uns" (Immanuel) begreift Takizawa als das Grundfaktum $^{21}$, das jeder durch Menschen vollzogenen Unterscheidung, beispielsweise jener zwischen Gott und Mensch, Glaube und Unglaube, Christ und Nicht-Christ, vorausgeht. Als Mensch gewordener Gottessohn ist Christus der sichtbar gewordene beziehungsweise zweite Immanuel. Anders als Karl Barth weiret Takizawa die Präsenz des zweiten Immanuel auf jeden Menschen, gleich welcher religiösen Herkunft, aus (201). Die darin zum Ausdruck kommende Überzeugung von der absoluten Gleichheit aller Menschen (180) ist nach Takizawa die einzige Grundlage, auf welcher der Dialog der Religionen gelingen kann.

Wie kaum einem anderen Theologen gelingt Pieris der interreligiöse Dialog aus der Mitte der christlichen zur Mitte der buddhistischen Tradition. Liebe und Weisheit treten zueinander in Beziehung und verschmelzen zu einem Ganzen, von dem aus betrachtet die Liebe ohne Weisheit ebenso mangelhaft erscheint wie die Weisheit ohne Liebe. Freilich gibt es in beiden Religionen auch eine Entsprechung zum Herzstück der anderen, und innerhalb beider findet ein wechselseitiges Durchdringen von Liebe und Weisheit (Gnosis) statt. Pieris zeigt an konkreten Beispielen auf, „daß es eine christliche Gnosis gibt, die notwendig von der Agape durchseelt ist, und daß es auch eine buddhistische Agape gibt, die gnostisch bleibt" (162). Für die interreligiöse Begegnung bringt er das Mönchtum ins Spiel, weil die aus Gottes-Erfahrung geborene mönchische Theologie dem östlichen Ethos und der östlichen Weisheit viel näher steht als die wissenschaftliche Theologie (145f). Pieris möchte aber auch innerhalb des Christentums die Kluft zwischen mönchischer und wissenschaftlicher Theologie überbrücken und schlägt deshalb vor, „daß Theologen ihren Dialog mit christlichen Mönchen, die nachdrücklich am östlichen Ethos teilnebmen, wieder aufnehmen “ (60).

Im Unterschied zu Yagi, Takizawa und Pieris bringt $D^{\prime} S_{a}$ das Christentum mit dem Hinduismus in Verbindung. Bei dieser Begegnung hat D'Sa stets vor Augen, daß es sich nicht nur um zwei Lehrgebäude oder Religionen, sondern um zwei höchst komplexe und in sich konsistente Traditionskreise handelt, aus denen man nicht Einzelaspekte herausbrechen und mit isolierten Segmenten der anderen Seite kombinieren darf. „Der Reduktionismus ist fehl am Platze, weil er die je andere Tradition nicht ernst nimmt, und der Synkretismus ist unerwünscht, weil er keine ernst nimmt" (131). Beides will D'Sa vermeiden, indem er, ehe er zum Dialog übergeht, zunächst die beiden Welten und Kulturen in ihren wesentlichen Merkmalen charakterisiert. Das anthropozentrische Weltbild des christlichen Abendlandes und das kosmozentrische Weltbild des hinduistisch geprägten indischen Subkontinents spiegeln seiner Erkenntnis nach beide Traditionskreise wider (37-58; als Kurzfassung dieser These vgl. auch D'Sa, „Das Recht, ein Mensch zu sein und die Pflicht, kosmisch zu bleiben“). Daß der Brückenschlag zwischen beiden Traditionen trotzdem möglich ist, will er am Beispiel der Got-

${ }^{21}$ Gelegentlich auch Urfaktum genannt; vgl. seinen Brief an J. Moltmann, a.a.O. 190 ff. 
teslehre aufzeigen. Die Dualität der personalen Gottesvorstellung im Christentum und der kosmischen Gottesvorstellung im Hinduismus macht auf beiden Seiten Defizite sichtbar. Deshalb D'Sa: „Ohne den Dreieinen Gott auf den AllGanzen zu reduzieren, wäre zu fragen, ob der Begriff des Dreieinen Gottes adäquat sein kann, wenn er nicht zugleich auch den Begriff des All-Ganzen enthält. Und umgekchrt: Ist der Begriff des All-Ganzen adäquat, ohne daß Gott auch der Dreieine ist?“ (77). D'Sa bezeichnet seinen Versuch als „Vorwort zur Begegnung zwischen Christentum und Hinduismus" (so der Untertitel). Wie könnte der Hauptteil eines interreligiösen Dialogs aussehen, der auf einer so breiten Basis angelegt ist, wie D'Sa es tut? Ich bin auf den Fortgang seines anspruchsvollen Vorhabens sehr gespannt.

\subsection{Bibel und christlicher Glaube in asiatischer Deutung}

Am Beispiel der folgenden Bücher und Dokumente soll ein Grundanliegen asiatischer Theologie hervorgehoben werden: die Deutung der biblischen Botschaft und des christlichen Glaubens "mit einem dritten Auge“. Den aus dem ZenBuddhismus stammenden Ausdruck verwendet Choan-Seng Song im Titel seines grundlegenden Werkes "Theologie des Dritten Auges ${ }^{42}$. Ein durch die asiatischen Lebensformen, Denkweisen und Verhaltensmuster erweiterter Erkenntnishorizont vermag Bereiche des Evangeliums und Glaubens aufzudecken, die im Umfeld der westlichen Kultur für lange Zeit unerkannt geblieben sind (21f). Für Menschen in Asien, einem überwiegend nichtchristlichen Kontinent, bieten sich die Bibelauslegung und Theologie "mit einem dritten Auge" als Tor zum christlichen Glauben an. Aber auch die Kirchen der Ökumene weltweit können und sollen sich ein drittes Auge verleihen lassen, um neue Dimensionen der Verkündigung zu entdecken. Die doppelte Blickrichtung - weg von der westlich dominierten hin zur asiatischen und von der asiatischen hin zur weltökumenischen Christenheit - charakterisiert Songs theologisches Denken. Sie entspricht dem Lebensweg des gebürtigen Taiwaners. In der presbyterianischen Kirche Taiwans aufgewachsen, hat ihn das Studium nach Edinburgh, Basel und New York geführt. Seine ökumenische Tätigkeit in der Christian Conference of Asia und im Weltrat der Kirchen (Abt. Glauben und Kirchenverfassung) befähigt ihn zu einer gesamtasiatischen Perspektive auf Theologie, die zugleich offen bleibt für eine über Asien hinausblickende multikulturelle Ökumene.

Nach der "Theologie des Dritten Auges" hat Song einen neuen methodischen Weg eingeschlagen, wie sich in seinen Hauptwerken aus den achtziger Jahren immer deutlicher herausstellt. ${ }^{23}$ Beispiel dafür ist der nur auf englisch veröffent-

${ }^{22}$ Leider fehlt in der deutschen Übersetzung ein Hinweis auf die vorgenommenen Kürzungen der Originalausgabe "Third Eye Theology“. Es fehlen das Vorwort sowie die Kapitel "The Seed of Hope in the Womb" und "The Transposition of Power".

${ }^{23}$ The Compassionate God. An Exercise in the Theology of Transposition, Maryknoll, $\mathrm{N}$. Y. 1982; Tell Us Our Names. Story Theology from an Asian Perspective, Mary Knoll, N. Y. 1984; Theology from the Womb of Asia, Maryknoll, N. Y. 1986. 
lichte Band "Theology from the Womb of Asia ". Hier hat sich Songs theologisches Denken in eine Stoffsammlung aufgelöst und sich damit vom Modell eines geschlossenen theologischen Entwurfs weit entfernt. Er reiht Fragmente von jeweils wenigen Seiten aneinander. Oft sind es Kurzgeschichten, die einen Aspekt gelebten Glaubens im Kontext von Asien erhellen. Das Ziel des Buches ist es, aus den reichen Quellen asiatischer Spiritualität, Leidenserfahrung und leidenschaftlichen Lebenswillens zu schopfen - Quellen, die vulkanartig aus dem „Mutterleib Asiens" (Womb of Asia) emporschießen (110ff). Die in Gruppen zusammengefaßten Fragmente sind mit den Stichworten Imagination, Passion, Kommunion und Vision überschrieben. Song befindet sich in diesem Werk auf der Suche nach einer interkulturellen Theologie. Die nächsten Aufgaben auf dem eingeschlagenen Weg zeichnen sich bereits ab: Einer interkulturellen Theologie müßte es gelingen, den erfahrungsbezogenen Stoffreichtum im Rückbezug auf die theologischen Hauptströme zu ordnen und zu einem konsistenten Ganzen zusammenzufügen.

Die Heilige Schrift mit indischen Augen lesen: davon gibt der Sammelband "Wir werden bei ihm wohnen - Das Johannesevangelium in indischer Deutung " einen beispielhaften Eindruck. Der am Päpstlichen Athenaeum in Poona (Indien) lehrende Neutestamentler George M. Soares-Prabhu SJ verweist auf die „bisher unbekannten Züge" des Joh, welche die zwölf in diesem Band dargebotenen Auslegungen sichtbar machen wollen (14). Weil, so der Herausgeber Soares-Prabhu, keine monokulturelle Interpretation der den Evangelientexten innewohnenden Sinnfülle gerecht zu werden vermag, ist der multikulturelle Horizont für eine sachgemäße Schriftauslegung unverzichtbar (ebd). Kennzeichnend für die Johannesexegese des Sammelbandes sind die Vorliebe für eine intuitive Textdeutung und die im Hinduismus üblichen Stilmittel des akademischen Diskurses, der Bildbetrachtung und Meditation. ${ }^{24}$ Die Nähe des Joh zum indischen Symbolismus hat mehrere Autoren bei der Auslegung inspiriert. Bei Michael A. Amaladoss SJ ( ${ }_{n}$ Ein Inder liest das Evangelium des heiligen Johannes", a. a.O. 19-34) wird die johanneische Einheitsperspektive von der hinduistischen Vision der Einheit (advaita) aus erhellt. Das Verhältnis des Sohnes zum Vater kann, so Amaladoss, mit der Ich-Du-Kategorie nicht angemessen bestimmt werden. In der Einheit von Vater und Sohn gibt es kein Du. „Da gibt es nur ein ,Ich', dessen Echo in verschiedenen Tiefen fortwährend wiederhallt" (29; ähnlich 149). Das Jesuswort "Ich bin“ (die Wahrheit, das Leben, das Licht ...) "reicht hinab bis in den tiefsten göttlichen Grund des Sohnes, ja weiter noch, in den des Vaters, denn der Sohn ist vom Vater. Gleichzeitig kann Jesus zum Vater beten und sich ihm

${ }^{24}$ Inzwischen gehört die Auslegung biblischer Texte im Medium der Kunst zu den wesentlichen Bestandteilen asiatischer Theologie. Masao Takenakas Aufsätze im Sammelbändchen „God is Rice“ zeugen davon. Am Beispiel des Magnifikat illustriert er, wie sich japanische Kunst und christlicher Glaube wechselseitig durchdringen und erhellen (Masao Takenaka, God is Rice. Asian Culture and Christian Faith, Genf 1986. 1989'). 
weihen ... Das ist wahrhaft das Mysterium des advaita (Einheit oder NichtZweiheit der Realität) “ (30).

Von den sonst in dieser Rezension zu besprechenden Texten heben sich zwei Dokumente $a b$, auf die nun einzugehen ist: die vom Chinesischen Christenrat verfaßte "Christliche Lehre" und das von Feliciano V. Cariño herausgegebene Glaubensbekenntnis der Vereinigten Kirchen Christi auf den Philippinen ("Gleich einem Senfkorn"). Als 1980 den chinesischen Kirchen zum ersten Mal seit langer Zeit wieder größere Freiheiten eingeräumt wurden, schlossen sich die Protestanten - knapp die Hälfte der fünf bis sechs Millionen Christen in China zum Christenrat zusammen. Nach dreijähriger Vorbereitungszeit legte dieser 1983 in Gestalt der "Christlichen Lehre" einen Katechismus „für alle Anfänger im Glauben “ vor, wie es im Untertitel der deutschen Übersetzung heißt. Unter häufigem Verweis auf biblische Worte faßt das Dokument mit bestechend einfachen Formulierungen die grundlegenden Merkmale des Glaubens zusammen. Einhundert Fragen und Antworten sind in sieben Abschnitte über die Bibel, Gott, Christus, den heiligen Geist, die Erlösung, die Kirche und die Heiligen gegliedert. Aus allen im Christenrat vertretenen konfessionellen Traditionen sollten die gemeinsam anerkannten Lehren übernommen werden (69). Punkte der Nichtübereinstimmung wurden ausgeklammert, um sie nicht zum Gegenstand wechselseitiger Kritik zu machen, $n$ weil diese Art von Meinungsverschiedenheiten nicht unsere Einheit im Herrn und unsere christliche Gemeinschaft beeinträchtigen sollte“ (70). An der Entstehung des Bekenntnisses haben mehr als einhundert Pastoren, Älteste und Laien aus allen Teilen des Landes mitgewirkt. Die große Resonanz, auf die es allenthalben stieß, erahnt man aus den Worten einer alten Chinesin:

"Es behandelt kurz und sachlich viele der Themen, die so viele Kinder Gottes verstehen wollen. Es umfaßt den grundlegenden Glauben und das Leben des Christen und behandelt die Wahrheit, den christlichen Weg und unsere Arbeit. Es ist Richtschnur und Kompaß in den Händen der älteren Christen, und es ist Regel und Maß für die Jungen und Begeisterten. Es bietet einen Abkürzungsweg für alle Christen an, die an dem geistlichen Wettlauf teilnehmen“ (73).

Vergleicht man diesen Katechismus mit der asiatischen Inkulturationstheologie, könnte der Kontrast kaum größer sein. Hier die „Anfänger im Glauben“ dort Gläubige der zweiten und dritten Generation; hier die Suche nach dem allerseits anerkannten Grundwissen im christlichen Glauben - dort das Risiko, auf unbekanntes Gelände vorzustoßen; hier das Bemühen um Einheit, ohne Uniformität zu erzwingen - dort die streitbare Auseinandersetzung mit den konfessionalistischen Altlasten; hier kaum ein Hinweis auf den religiösen und kulturellen Kontext - dort die Versenkung der christlichen Lehre in die asiatische Welt. Bei genauerem Hinschauen werden trotz allem auch Gemeinsamkeiten erkennbar. Beides kann Ausdruck einer asiatisch geprägten Auffassung des christlichen Glaubens sein: die Verschmelzung mit asiatischen Denk- und Lebensformen und die Suche nach einem christlichen Grundkonsens in bewußter Unterscheidung 
zur kulturell-religiösen Umwelt. Nur die eine Form als asiatisch zu akzeptieren wäre unangemessen und würde vor allem nicht der Gleichzeitigkeit des Ungleichzeitigen Rechnung tragen, das im Leben der Christenheit immer schon eine entscheidende Rolle gespielt hat.

Auch das Glaubensbekenntnis der (protestantischen) Vereinigten Kirche Christi auf den Philippinen ("Gleich einem Senfkorn", A 5f) ist ein Versuch, aus höchst disparaten konfessionellen Traditionen den gemeinsamen Glauben zu artikulieren. Fast vierzig Jahre brauchte die 1948 gegründete Union, bis das Glaubensbekenntnis in dieser Form gefunden war. Deutlicher als beim chinesischen Katechismus spürt man in dem 7 Artikel umfassenden philippinischen Dokument den Bezug zu den brennenden gesellschaftlichen Fragen. Auf den engen Zusammenhang von Bekennen und sozialem Engagement verweisen die namhaften philippinischen Theologen in ihren Erläuterungen zu einzelnen Artikeln des Bekenntnisses $(1-69)$.

\subsection{Inkulturation und Befreiung}

"Es gibt hierzulande (sc. in Indien, C. L.) keine theologische Konferenz ohne Konfrontation zwischen ,Ashramiten', die die Inkulturation der christlichen Theologie in einheimische Denkformen fordern, und ,Befreiungsorientierten", die im Evangelium den Ruf zu sozialer Gerechtigkeit sehen" (Soares-Prabbu, 15). Nach Einschätzung von Soares-Prabhu ist es auch in den indischen Beiträgen zum Johannesevangelium ( W Wir werden bei ihm wohnen “) nicht gelungen, Inkulturation und Befreiung miteinander zu verbinden. „Die indologischen und soziologischen Deutungen verlaufen parallel zueinander und treffen nirgendwo zusammen" (ebd). Immerhin versucht $D^{\prime} S a$ in seinem Beitrag zum Sammelband ${ }^{25}$, die soziale Bedeutung des Joh von dessen symbolischen Bildern her aufzuzeigen: Brot kann nur dann Zeichen des Lebens sein, wenn es geteiltes Brot ist $(121)^{26}$

Angesichts der schwierigen Aufgabe, im Kontext von Südasien beide Anliegen miteinander zu verbinden, ist um so bemerkenswerter, daß genau dieses Aloysius Pieris gelingt. "Der, asiatische Kontext' kann als eine Mischung tiefgründiger $\boldsymbol{R} \boldsymbol{e}$ ligiosität ... und erschütternder Armut beschrieben werden" (Liebe und Weisheit, 61). Deshalb soll die Kirche in den Jordan dieser Religionen tauchen (getauft werden) und sich zugleich den Armen zuwenden, indem sie Armut praktiziert als einen Protest und eine vorbeugende Maßnahme gegen aufgezwungene Armut (59ff). Diesen Ansatz hat Pieris ausführlich in "Theologie der Befreiung in Asien" entfaltet. ${ }^{27}$

Der von Felix Wilfred herausgegebene Sammelband „Verlaß den Tempel. An.

${ }^{25}$ Sehen - Glauben - Innewohnen. Joh 1 als hermeneutisches Modell, in: Soares-Prabhu, a.a. O. 99-121.

${ }_{26}$ Auch bei Soares-Prabhu klingt beides an, vgl. Der Blindgeborene. Verständnis eines johanneischen Zeichens im heutigen Indien, a.a.O. 142-156.

27 Näheres dazu bei V. Küster in diesem Heft. 
tyodaya - indischer Weg zur Befreiung “ hat die religiöse und kulturelle Verwurzelung der Befreiungstheologie in Indien zum Ziel. Mehrere Beiträge stehen somit unter der Leitfrage, wie das hinduistische Verständnis von Befreiung und die Befreiung naus den Fängen des Todes, der Zerstörung und der Unmenschlich-

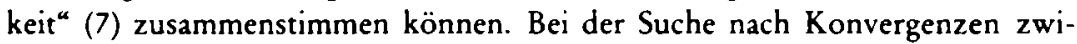
schen den zunächst grundverschieden erscheinenden Befreiungskonzepten stößt Sebastian Painadath auf "eine Unterströmung der sozialen Sorge in den Schriften und geistlichen Traditionen des Hinduismus. Der Begriff der Befreiung (mukti) ist nicht völlig negativ im Hinblick auf die Werte irdischen Wohlergehens und sozialer Veränderung. Die hinduistische Ethik verlangt allgemein, daß der Mensch das letztendliche Heil (moksha) durch den rechten (dharma) Gebrauch der materiellen Güter ( $a r t h a$ ) und die richtige Steuerung der psychischen Energie (kama) erlangt. ${ }^{\text {"28 }}$ Statt die hinduistischen und christlichen Dimensionen von Befreiung als Kontraste gegeneinander auszuspielen, machen die Autoren auf deren wechselseitige Beeinflussung im Austausch von Hinduisten und Christen aufmerksam. Nicht nur das christliche Befreiungsethos gewinnt im religiösen Pluralismus Indiens eine eigene Prägung. Auch der Hinduismus hat aufgrund befreiungstheologischer Impulse aus dem Christentum sein Gesicht verändert (206). ${ }^{29}$ Eine genuin indische Befreiungstheologie ist indessen erst im Entstehen begriffen, wie der Herausgeber selbst bemerkt. Er nennt sie seiner eigenen Wortschöpfung gemäß "Antyodaya"-Theologie und meint damit eine Theologie, welche sich auf die „einzigartige Erfahrung der Erhebung der Ärmsten“ bezieht (17).

Es wäre interessant, die indische mit der südkoreanischen Variante der Befreiungstheologie zu vergleichen. Dabei könnte sich herausstellen, daß es innerhalb Asiens recht verschiedenartige Ansätze gibt. Wie verhält sich beispielsweise das "Leiden ohne Zorn und Groll“, das nach dem indischen Verständnis zur Befreiung gehört (Wilfred, 15), zum koreanischen han, jenem Zorn und Groll über erlittenes Unrecht, welche der Minjungtheologie zufolge eine treibende $\mathrm{Kraft}$ der Befreiung sind? Fordert die indische Befreiungstheologie, die "ein kreatives Gleichgewicht wahrt zwischen dem Geschichtlichen, dem Ethischen und Empirischen und dem Ontischen " (14) die Minjungtheologie nicht genauso heraus wie die lateinamerikanische Befreiungstheologie? Möglicherweise gibt es einen weiteren Unterschied beim Verständnis der Inkulturation. Während die Minjungtheologie ausschließlich auf die Verwurzelung in der Kultur des unterdrückten Volkes setzt, die sie als Gegenkultur zu jeder Herrschaftsideologie einschließlich des Neokonfuzianismus begreift, ist eine Konfrontation zum Hinduismus als Herrschaftsideologie in den Beiträgen aus Indien nicht zu erkennen. Vielmehr knüp-

${ }^{28} M u k t i$ - der hinduistische Befreiungsbegriff und seine Bedeutung für eine indische Theologie der Befreiung, a.a.O. 51-68 (Zit. 67); vgl. ferner X. Irudayaraj, Innerlichkeit kontra Befreiung?, a.a.O. 116-127.

${ }^{29}$ Zur Illustration dazu vgl. M. M. Thomas, Christus im neuen Indien. Reformhinduismus und Christentum, Göttingen 1989. 
fen sie an den Hinduismus als der bedeutendsten Religion Indiens an und deuten zentrale hinduistische Begriffe aus befreiungstheologischer Perspektive.

Ein Hinweis auf neuere Veröffentlichungen zur Minjungtheologie muß hier genügen. " Von Byung-Mu Ahn sind 1986 mehrere theologische Beiträge auf deutsch erschienen in "Draußen vor dem Tor". Ergänzend dazu findet man in der Heidelberger Dissertation von Andreas Hoffmann-Richter mit dem Titel "Ahn Byung-Mu als Minjung-Theologe“ aufschlußreiche Hinweise zu Ahns Leben und Werk. Hoffmann-Richter hat die Kontinuität und Diskontinuität zwischen dem jungen $\mathrm{Ahn}$ in Heidelberg (!) und der späteren Theologie naus der Perspektive des Minjung" herausgearbeitet. Vor kurzem sind von David Kwang-Sun Suh, Presbyterianer wie viele unter den Minjungtheologen, in einer englischen Ausgabe mehrere Beiträge erschienen ("The Korean Minjung in Christ $^{*}$ ). Darin wird das minjungtheologische Verständnis von Inkulturation ausführlich entfaltet: die biblische Befreiungsbotschaft verschmilzt mit der koreanischen Gegenkultur, also den vielfältigen Manifestationen des Volksprotests gegen die religiöse und politische Kultur der Herrschenden. Als Beispiele behandelt Suh in Verbindung mit dem Minjung den Schamanismus (als Religion des han), den Maitreya-Buddhismus und den „Maskentanz der Befreiung“. Den geschichtlichen Wurzeln des Messianismus in den verschiedenen Religionen und sozialrevolutionären Bewegungen Koreas ist Soo-Il Chai in "Die messianische Hoffnung im Kontext Koreas" nachgegangen. Der inzwischen in seine Heimat zurückgekehrte Koreaner hat in seiner Studie (ebenfalls eine Heidelberger Dissertation) wichtiges Hintergrundmaterial zum Verständnis der Minjungbewegung und Minjungtheologie zusammengetragen. Chai teilt die Grundüberzeugungen der Minjungtheologen. Es ist zu hoffen, daß seine kritischen Fragen zur politischen Ethik im Kreis der Minjungtheologen als weiterführender Impuls aufgenommen werden (vgl. bes. 157-176).

Auf den Philippinen hat das Christentum zwei Formen angenommen, zwischen denen es nur wenig Berührungspunkte gibt: die offizielle (katholische) Kirche und den Volkskatholizismus. Während sich erstere von den nabergläubischen" bzw. "häretischen" Tendenzen in letzterer distanziert, hat sich die einfache Bevölkerung das Christentum so zu eigen gemacht (inkulturiert!), daß die vorchristliche Religiosität im Christentum als einem neuen Gewand weiterleben kann. Davon zeugen die populären Frömmigkeitsübungen, Prozessionen, Gebete, Rituale und vor allem die Verehrung religiöser Bilder. Der Theologieprofessor und Priester Benigno P. Beltran will beide Traditionsströme zueinander in Beziehung setzen; denn sie müssen sich, wie er sagt, wechselseitig herausfordern und durchdringen ("Philippinische Theologie in ihrem kulturellen und gesellschaftli-

${ }^{30}$ Zum Begriff "minjung" sowie zu den Anfängen der Minjungtheologie vgl. meinen Artikel: Kontextuelle Theologie in Südkorea: Das Beispiel der ,Minjung-Theologie', in: VF 30, $1 / 1985,65-70$. Eine Bibliographie zur Minjungtheologie bis 1989 hat Wolfang Kröger zusammengestellt, in: Evangelisches Missionswerk ( $\mathrm{Hg}$.), Minjung-Theologie - ein Briefwechsel (Weltmission heute 5), Hamburg 1983, 34-39. 
chen Kontext ${ }^{\text {}}$ ). Statt den eigenen Vorurteilen zu vertrauen, sollten sich Vertreter der offiziellen Kirche um ein besseres Verständnis des Volksglaubens bemühen. Beltran würdigt die Bilderverehrung im Volkskatholizismus als "Theologie der Sprachlosen " und zeigt Entsprechungen zwischen der Bild- und Worttheologie auf (120ff). Die Unterscheidung zwischen notwendiger Inkulturation und verfälschendem Synkretismus ist eine Aufgabe, der sich die offizielle Kirche und Kenner der Volksfrömmigkeit gemeinsam stellen müssen. Selbstzerstörerische Elemente der philippinischen Volksreligiosität christlicher Prägung zeigen sich laut Beltran in jenem Feiern der Passion, das nichts vom Auferstehungsgeschehen erkennen läßt. Ein solcher Passionsglaube verstärke auch den Hang zur politischen Passivität. Um der Resignation angesichts der elenden Lebensverhältnisse entgegenzuwirken, sei es notwendig, nicht nur von der Geburt und vom Tod Jesu, sondern ebenso über dessen Verkündigungsjahre zu berichten. Eine philippinische Christologie müßte demnach zeigen, wie Jesus „herausfordert, provoziert, konfrontiert, Leute zu einer endgültigen Entscheidung ruft, Heuchler anprangert, die Reichen warnt, den Armen die Gute Nachricht verkündet, kämpft, und schließlich hungrig, durstig und müde ist wie wir" (145). Eine gelungene Verbindung von Inkulturation und Befreiung hat Beltran in den christlichen Basisgemeinden kennengelernt, das heißt bei den Menschen auf "Smokey Mountain“, der Müllkippe in Tondo, einem Slum von Manila.

Was Beltran als philippinische Christologie umrissen hat, ist der Ausgangspunkt der Publikation "Theologie des Kampfes“, die insgesamt 25 Zeugnisse der "christlichen Nachfolgepraxis in den Philippinen " dokumentiert, wie es im Untertitel heißt (hg. von Mary Rosario Battung u. a.). Gedichte, ein Gebet, Augenzeugenberichte, Ansprachen, Aufsätze und Bibelexegesen bilden ein breites Spektrum von Gedanken über den christlichen Glauben „in einer Situation des Kampfes“. Persönliche Erfahrungen sowie Beobachtungen von Menschenrechtsgruppen, ökumenischen Gremien, Frauenorganisationen, diakonischen Einrichtungen und politischen Bewegungen werden im Horizont einer philippinischen Befreiungstheologie reflektiert.

In den Beiträgen zu Inkulturation und Befreiung begegnet eine Differenz zwischen Autoren und Autorinnen. Befreiung ist in den feministischen Beiträgen aus Asien die grundlegende Kategorie, Inkulturation dagegen steht unter einem yroBen Fragezeichen. „Ohne Befreiung keine Inkulturation“ - so könnte man das gemeinsame Anliegen feministischer Theologinnen umschreiben. Ihre Kritik am patriarchalen Charakter asiatischer Kulturen ist grundsätzlicher Art und wird von ihren männlichen Mitstreitern im politischen Kampf nie in dieser Deutlichkeit und Ausführlichkeit artikuliert. Die Indonesierin Marianne Katoppo beschreibt den dreifachen Zwiespalt zwischen asiatischer Kultur, westlichem Christentum und patriarchaler Gesellschaftsordnung ( logie einer asiatischen Frau“). Sung-Hee Lee-Linke, eine in Deutschland lebende Koreanerin, spricht als asiatisch-feministische Theologin ihre Vorbehalte gegenüber der von Männern konzipierten Befreiungstheologie offen aus. Lee-Linke 
schreibt: "Sie teilen eine Gesellschaft nur in den Gegensatz von Machthabern und Machtlosen ... In dieser Hinsicht stellen die Machtkämpfe zwischen unterdrückenden und unterdrückten Männern in der Befreiungstheologie interne Kämpfe des Patriarchats dar ( ${ }^{\circ}$ Frauen gegen Konfuzius. Perspektiven einer asiatisch-feministischen Theologie“, 208). Eingeschlossen in die Kritik ist auch die Minjungtheologie, welcher Lee-Linke - nach meiner Einschätzung nicht ganz zu Recht - vorhält, „daß die Frauenrechte auch in ihr eigentlich nicht berücksichtigt“ werden (ebd.). Aus den Äußerungen asiatischer Theologinnen spricht die Sehnsucht nach einem Leben, das der kulturellen Identität, dem Anspruch auf Freiheit und Gleichberechtigung sowie der christlichen Existenz gleichermaßen gerecht wird. Sie lassen sich von verschiedenen Quellen her inspirieren. Bei Katoppo ist es die Auslegung der Bibel aus der Sicht einer Frau und bei Lee-Linke eine Theologie der Versöhnung zwischen den Klassen und Geschlechtern. Die Koreanerin Hyun-Kyung Chung, die auf der 7. Vollversammlung des Weltrates der Kirchen in Canberra im Februar 1991 aufgetreten ist, erläutert ihren Ansatz schließlich damit, $\mathrm{daB}$ sie mittels befreiungsorientierter Elemente aus verschiedenen Religionen und Kulturen einen „befreiungsorientierten Synkretismus“ anstrebt. ${ }^{31}$

"Vgl. vor allem Hyun-Kyung Chung, "Opium oder Keim der Revolution?" Schamanismus: Frauenorientierte Volksreligiosität in Korea, in: Concilium 24, 1988, 393-398 (bes. 394f); ferner dies., Auf den Spuren eines langen Traumes, in: Letty $\mathrm{M}$. Russel ( $\mathrm{Hg}$.), In den Gärten unserer Mütter. Religiöse Erfahrungen von Frauen heute, Herder Freiburg 1990, 52-70 (bes. 66f).

\section{Aufbruch der Dritten Welt}

Der Weg der ökumenischen Vereinigung von Dritte-Welt-Theologen [EATWOT]

Volker Küster

1. Konferenzakten: Sergio Torres/Virginia Fabella $\left(\mathrm{Hg}_{\mathrm{g}}\right)$, The Emergent Gospel Theology from the Developing World. Papers from the Ecumenical Dialogue of Third World Theologians, Dar es Salaam, August 5-12, 1976, XXIII + 275 S. Chapman London 1978. - Kofi Appiah-Kubi/Sergio Torres, African Theology en Route. Papers from the Pan-African Conference of Third World Theologians, December 17-23, 1977, Accra, Ghana, X + 214 S. Orbis Books Maryknoll, New York 1979. - Virginia Fabella (Hg.), Asia's Struggle for Full Humanity. Towards a Relevant Theology. Papers from the Asian Theological Conference, January 7-20, 1979, Wennappuwa, Sri Lanka, VI + 202 S. Orbis Books Maryknoll, New York 1980. - Sergio Torres/John Eagleson (Hg.), The Challenge of Basic Christian Communities. Papers from the International Ecumenical Congress of Theology, February 20March 2, 1980, Sao Paulo, Brazil, VII + 283 S. Orbis Books Maryknoll, New York 19883. - Virginia Fabella/Sergio Torres (Hg.), Imuption of the Third World. Challenge to Theolo- 